\title{
A fresh look at the costs of non-fatal consumer product injuries
}

\author{
Bruce A Lawrence, Rebecca S Spicer, Ted R Miller
}

Pacific Institute for Research and Evaluation, Calverton, Maryland, USA

Correspondence to Dr RS Spicer, Pacific Institute for Research and Evaluation 11720 Beltsville Drive, Suite 900, Calverton, MD 20705-3111, USA; spicer@pire.org

Received 24 February 2014 Revised 16 June 2014 Accepted 1 July 2014 Published Online First 1 August 2014

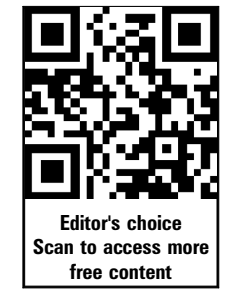

CrossMark

To cite: Lawrence BA, Spicer RS, Miller TR. Inj Prev 2015;21:23-29.

\section{ABSTRACT}

Background Products under the purview of the Consumer Product Safety Commission are involved in a large share of injuries and injury costs in the USA. Methods This study analyses incidence data from the National Electronic Injury Surveillance System (NEISS) and cost data based on the Injury Cost Model, integrated with the NEISS. We examined the magnitude of nonfatal consumer product related injury, the distribution of products involved in these injuries and the cost of these injuries. We compared these findings with an earlier identical study from 2000.

Results In 2008-2010, 43.8\% of the annual 30.4 million non-fatal injuries treated in hospital emergency departments involved consumer products. Of these consumer product related injuries, in 2009-2010, just three product groups accounted for $77 \%$ of the $\$ 909$ billion annual cost: sports and recreation; home structures and construction materials; and home furnishings and fixtures. Sports and recreation was a leading cause of injury costs among 5-24-year-olds, particularly football, basketball, bicycling, baseball/ softball and soccer. Since 1996, football surpassed basketball in becoming the number one cause of injury costs for children aged 10-19 years and the fifth ranked cause of product related injury costs overall. Among those over age 30 years, stairs and floors were a leading cause of consumer product related injury costs, in particular among those over age 70 years where they were responsible for over one-fifth of costs.

Conclusions The findings of this study highlight priority areas for intervention and generate questions for future research.

\section{INTRODUCTION}

Consumer products are used extensively across a wide range of settings-homes, workplaces, daycare centres and schools-and are involved in a significant proportion of injuries. Annually, these product related injuries account for approximately $29 \%$ of unintentional injury deaths. The USA Consumer Product Safety Commission (CPSC) has jurisdiction over products and their related injuries, with the exception of injuries involving tobacco, drugs, pesticides, food, medical devices, boats, aircraft, firearms and motor vehicles.

Consumer product injury analyses are facilitated by CPSC's National Electronic Injury Surveillance System (NEISS). With NEISS, CPSC collects information on consumer product injuries treated in hospital emergency departments (EDs). Integrated within NEISS is the Injury Cost Model (ICM), which allows us to estimate the medical costs, work losses, pain and suffering costs, and product liability, insurance administration and litigation costs of these injuries. ${ }^{1}$ While incidence data are useful for assessing the magnitude of the problem, costs better account for multiple injury consequencesdeath, severity, disability, body region, nature of injury-in a single unit of measurement. Cost analyses are useful for comparing injury causes, assessing related health burden, setting priorities and planning cost effective prevention strategies.

Previously, using 1995-1996 NEISS data, Lawrence $e t a l^{1}$ developed and used the ICM to estimate the costs associated with non-fatal injuries related to products under CPSC jurisdiction. They found that consumer product injuries cost approximately $\$ 500$ billion per year in 1995-1996, accounting for nearly one-third of injury costs in the USA.

This aim of this article was to update these estimates of consumer product injury costs by applying the ICM to NEISS data from 2009 to 2010 . We further examined the leading products responsible for non-fatal injury costs in 2009-2010 compared with 1995-1996.

\section{METHODS}

NEISS is a weighted national probability sample of consumer product related injury visits to EDs in a sample of 100 US hospitals. Overall, NEISS includes data on approximately 400000 ED injury visits per year. The NEISS data provided detailed information on consumer product related injuries.

Since 2000, 66 of the 100 NEISS hospitals have participated in an expanded collection effort that covers all injuries, not just those involving consumer products. This expanded system, called the NEISS All Injury Program (NEISS-AIP), collects data on more than 500000 ED injury visits per year, both intentional and unintentional. The NEISS-AIP data provided a more comprehensive context to understand the per cent contribution of consumer product related injury to the overall injury problem.

Thus we constructed two different datasets for our analysis. For the first, we combined NEISS data from 2009 and 2010, dropping all fatalities. ${ }^{i}$ Using the current version of the ICM, we estimated four types of costs in 2009 dollars for each case: medical costs, work loss, pain and suffering, and legal and liability expenses. When summed, these

${ }^{\mathrm{i}} \mathrm{NEISS}$ is not a suitable dataset for analysing fatal injuries. Because it is collected in EDs, NEISS can capture only those deaths that occur during the brief time after arrival at the ED and before discharge or inpatient admission-a small and unrepresentative sample of injury deaths. Moreover, the Injury Cost Model is designed to cost only the non-fatal injuries in NEISS. 
represent the total long term cost of an injury to society. This dataset was used to look at the costs of consumer product injuries during 2009-2010 and contained nearly 800000 product related injury cases.

NEISS data are collected only from hospital EDs. However, many injuries are treated in other settings, such as doctor's offices and standalone clinics. A few of these patients are even admitted to a hospital without being processed through an ED. In order to account for these cases, the ICM includes ratios of non-ED injuries to ED treated injuries. For the non-admitted, non-ED injuries, the ICM includes separate cost estimates. These features of the ICM enable CPSC to estimate the total incidence and costs of consumer product injuries, including those that are not represented directly through the ED based NEISS sample. This ability to cover non-ED injuries applies only to consumer product injuries. It could not, therefore, be extended to the broader NEISS-AIP.

Injuries were classified according to the CPSC product code. CPSC considers the injury sport related if it involves the use of a consumer product that is in play (ball, stick, etc) or a piece of apparatus that is in use. Sport related injuries include injuries to both players and spectators. We did not further explore each case narrative to classify the injury or to identify the aetiology or other case information.

For the second dataset, we combined NEISS-AIP data from 2008 to 2010, dropped the fatalities and merged on product codes from the NEISS data for these same years. We used 3 years in order to obtain a reliable sample size. As the ICM was built to cost only consumer product injuries, it is not appropriate for costing the non-product cases in NEISS-AIP. Injuries resulting from violence, motor vehicle collisions (MVCs) or occupational incidents, for example, have a different cost profile than consumer product injuries. The NEISS-AIP, as a subsample of NEISS hospitals, includes all NEISS cases-that is, all consumer product related cases-from those hospitals plus other cases that are not product related. By merging product codes onto the product related cases, we were able to identify the product related cases in NEISS-AIP. This augmented 3 year NEISS-AIP dataset was used to examine the place of consumer product injuries in the broader injury context. As the dataset was not costed, we used it only for incidence comparisons. This dataset contained about 1.5 million cases, including 650000 consumer product cases that were also in NEISS.

\section{RESULTS}

\section{Consumer product injuries in relation to all ED treated injuries}

According to the NEISS-AIP, in 2008-2010, 43.8\% $(13.3$ million injuries) of the annual 30.4 million injuries treated in hospital EDs involved products under the purview of the CPSC. The largest product category, sports and recreation, accounted for $13.7 \%$ of all ED treated injuries (11 853634 injuries), 48\% more injury visits to the ED than motor vehicle occupant injuries (8 009038 injuries; a category not under CPSC purview). Among teenage boys, football injuries alone (742 269) outnumbered motor vehicle occupant injuries (476 919).

\section{Incidence of consumer product injuries}

Of the 13.3 million consumer product related injuries treated in hospital EDs annually, the leading precipitating causes of product related injuries were fall $(39.3 \%)$, struck by/against (22.9\%), overexertion (12.3\%) and cut/pierce (10.4\%). The leading products were stairs/steps $(8.6 \%)$, floors $(6.5 \%)$, beds
(4.2\%), bicycles (3.7\%), basketball (3.6\%), football $(3.4 \%)$, knives $(2.4 \%)$, doors $(2.4 \%)$ and chairs $(2.3 \%)$.

The largest product category, sports and recreation, accounted for nearly one-third of product related injuries. The leading precipitating causes of sports/recreation related injuries were struck by/against $(27.4 \%)$, fall $(21.5 \%)$, overexertion $(21.3 \%)$ and pedal cyclist (12.4\%). The leading activities were bicycling (12.4\%), basketball (11.9\%), football (11.2\%), baseball/softball (6.6\%), exercise (5.9\%), playground (5.5\%) and soccer (5.0\%).

\section{Costs of consumer product injuries}

The burden of non-fatal product related injury was analysed using the costed NEISS file.

As shown in table 1, in 2009-2010, three product categories accounted for $77 \%$ of the $\$ 909$ billion annual cost of medically treated product related injuries:

- sports and recreation (30\%);

- home structures and construction materials (27\%);

- home furnishings and fixtures (20\%).

The top 10 individual products in terms of non-fatal injury cost (table 2) came from these three categories. Home structures included stairs/steps (No 1) and floors (No 2); home furnishings and fixtures by beds and bedding (No 3), chairs (No 7), bathtubs and showers (No 8), and ladders (No 9); and sports and recreation by bicycles (No 4), football (No 5), basketball (No 6) and exercise (No 10). The first product not in one of these three categories, all-terrain vehicles, ranked 16 th.

Injuries related to home furnishings and fixtures were concentrated among young children and older adults. Home structures, by contrast, were involved in injuries at every stage of life. In fact, as shown in table 3 , the top two products from this category, stairs/steps and floors, were both among the top four products associated with injury costs for every age group except children and young adults, ages 5-24 years. At these ages, sports and recreation came to the fore, particularly football, basketball, bicycling, baseball/softball and soccer, as shown in table 4 . In this age range, $59 \%$ of all product related injury costs were related to sports and recreation, compared with $25 \%$ at other ages. Conversely, 54\% of all sports and recreation injury costs resulted from injuries incurred by 5-24-year-olds (data not shown). As participation in competitive team sports falls through the 20 s and 30 s, so do the aggregate costs of injuries associated with these sports. The only sports and recreation activities that continued to be top sources of injury costs after age 40 years were bicycling and exercise.

The NEISS-AIP incidence data showed that basketball accounted for more injuries than football. However, football injuries accounted for a greater share of injury costs than basketball because of the higher cost per injury, suggesting more severe injuries on average.

Consumer products related to the most severe injuries, measured by cost per injury, included horseback riding, bathtub showers and manual snow/ice tools (table 2).

\section{Trends in sports and recreation injury costs}

Since we last looked at consumer product injuries more than a decade ago, based on the 1995-1996 NEISS data, patterns of sports and recreation injuries have changed. We will further examine tables 2 and 3 to highlight these changes.

Bicycling remains the number one cause of sports/recreation related injuries and the third ranked cause of product related injuries overall, but its share of injury costs has fallen from $6 \%$ to $4 \%$. Its share of injuries at ages 5-9 years fell from $14 \%$ to 
Table 1 Annual costs of non-fatal consumer product injuries by product group, 2009-2010 (2009 dollars)

\begin{tabular}{|c|c|c|c|c|}
\hline Product group & Annual total cost (\$) & Percentage & Annual incidence & Mean cost (\$) \\
\hline Sports and recreation & 269501000000 & 29.6 & 4273620 & 63062 \\
\hline Home structures and construction materials & 248708000000 & 27.4 & 3578616 & 69498 \\
\hline Home furnishings and fixtures & 184615000000 & 20.3 & 2678972 & 68913 \\
\hline Miscellaneous products & 29199000000 & 3.2 & 366072 & 79763 \\
\hline Personal use items & 27422000000 & 3.0 & 557401 & 49196 \\
\hline Housewares (non-powered) & 23698000000 & 2.6 & 684801 & 34606 \\
\hline Yard and garden equipment & 21491000000 & 2.4 & 300682 & 71473 \\
\hline Packaging and containers & 20224000000 & 2.2 & 354850 & 56992 \\
\hline Toys & 19109000000 & 2.1 & 374087 & 51083 \\
\hline Home workshop equipment & 18256000000 & 2.0 & 369362 & 49425 \\
\hline Home electronics and hobby & 9192000000 & 1.0 & 149089 & 61656 \\
\hline Kitchen appliances & 7636000000 & 0.8 & 115805 & 65939 \\
\hline Space HVAC appliances & 6765000000 & 0.7 & 113795 & 59447 \\
\hline Products covered by existing regulations & 6534000000 & 0.7 & 116155 & 56250 \\
\hline Home/family maintenance & 6249000000 & 0.7 & 128491 & 48637 \\
\hline Child nursery equipment & 5937000000 & 0.7 & 89742 & 66154 \\
\hline Household appliances & 3848000000 & 0.4 & 54768 & 70268 \\
\hline Other categories* & 1097000000 & 0.1 & 18506 & 59302 \\
\hline Total & 909481000000 & 100.0 & 14324811 & 63490 \\
\hline
\end{tabular}

* Other categories include farm supplies and equipment; home alarm/escape/protection; school equipment; and poisoning (age $<5$ years).

$8 \%$, and similar drops were found for all ages through the 30 s. At ages 50-69 years, however, bicycling now accounted for a greater share of injuries than previously. Skating, which formerly ranked between fifth and eighth for ages 5-19 years, now barely registered at 12 th for ages 10-14 years. ${ }^{\text {ii }}$ The place formerly occupied by skating is now occupied by skateboards among children aged 10-19 years, and to some extent by scooters for children of 5-9 years.

There have also been shifts in the patterns of injury costs related to popular team sports. Overall, football has risen from seventh to fifth, surpassing both basketball, which fell from fourth to sixth, and baseball/softball, which dropped from sixth to 13 th. Football is now the top cause of product related injuries at ages 10-19 years, and it has also moved up the list for ages 5-9 years and 20-29 years. For ages 10-14 years, football has risen from $9 \%$ of all product related injuries to $14 \%$. Meanwhile, the share of injuries associated with basketball has fallen dramatically, from $5 \%$ to $3 \%$ overall, and by $2-4$ percentage points for each age group in the 10-39 year range. Similarly, the share of injuries associated with baseball/softball has fallen by about 1 percentage point for each age group. Soccer is now responsible for more injury costs than baseball/ softball at ages 10-19 years, but not at other ages.

At ages 5-9 years, various types of playground apparatus are major causes of injury. Monkey bars remained the second ranked product for this age, just after bicycles. However, swings have fallen from third to ninth while trampolines have risen from 10th to sixth, with corresponding changes in percentages. Slides moved onto the list of top products at 1-th. Among children 10-14 years, trampolines held steady at $2 \%$ of injury costs.

Two activities that formerly accounted for significant shares of injury costs among the middle aged declined. Snow skiing,

ii In our analysis of the 1995-1996 data, we combined in-line skating and roller skating. Now CPSC combines all types of skating-roller, in-line and ice-in a single category. which ranked third to sixth at ages 40-69 years and accounted for as much as $6 \%$ of injury costs at ages 50-59 years no longer made the list of the top 12 injury causes for any age group. Also, horseback riding, which accounted for $2 \%$ of injury costs at ages 40-59 years now accounted for just 1\% of injury costs for ages 50-59 years.

Exercise (defined as exercise without special equipment, such as aerobics, stretching or jogging) was ranked 10th overall. Exercise ranked seventh for the 20 s through to the 50 s, and ninth in the $60 \mathrm{~s}$.

\section{Trends in injury costs related to home structures and furnishings}

While stair/step related injuries comprised the largest proportion of overall product injury costs, ${ }^{2}$ their contribution decreased substantially for the <1 year age group compared with 19951996, when stairs and steps were the leading contributor at $15 \%$ of total product injury costs for this age group. In 20092010, stairs and steps were the fourth leading cause among children under 1 year of age, at $6 \%$ of total injury costs. Among $1-$ 4-year-olds, stairs still contributed substantially (7\%, compared with $8 \%$ in 1995-1996) to injury costs along with other home structures (floors, doors, ceilings and walls). Among those aged 20 years and older, home structures (stairs/steps and floors) continued to be leading contributors to injury costs.

Home furnishings were substantial contributors to injury costs, particularly among infants less than 1 year of age: beds and bedding alone accounted for $22 \%$ of product related injury costs, with sofas, tables and chairs contributing another $13 \%$. These shares have increased since 1995-1996, when $11 \%$ of costs were bed related and another $11 \%$ were related to the other four products. Among 1-4-year-olds, these four products accounted for $23 \%$ of product related injury costs in 2009 2010-slightly greater than the 19\% share in 1995-1996.

Among those age 60 years and above, bathroom related injuries (primarily bathtubs, showers and toilets) contributed 
Table 2 Leading products involved in injury, ranked by non-fatal injury cost, 2009-2010 (2009 dollars)

\begin{tabular}{|c|c|c|c|c|c|}
\hline Rank & Product & Annual total cost (\$) & Percentage & Annual incidence & Mean cost (\$) \\
\hline 1 & Stairs & 92294000000 & 10.1 & 1231619 & 74937 \\
\hline 2 & Floors & 81233000000 & 8.9 & 941296 & 86299 \\
\hline 3 & Beds & 44192000000 & 4.9 & 612658 & 72131 \\
\hline 4 & Bicycles & 38898000000 & 4.3 & 536360 & 72521 \\
\hline 5 & Football & 27127000000 & 3.0 & 467575 & 58016 \\
\hline 6 & Basketball & 25677000000 & 2.8 & 508167 & 50529 \\
\hline 7 & Chairs & 22377000000 & 2.5 & 335180 & 66761 \\
\hline 8 & Bathtubs/showers & 19723000000 & 2.2 & 262849 & 75037 \\
\hline 9 & Ladders & 18662000000 & 2.1 & 179195 & 104144 \\
\hline 10 & Exercise (w/o equipment) & 16135000000 & 1.8 & 211682 & 76224 \\
\hline 11 & Doors & 15914000000 & 1.7 & 334868 & 47522 \\
\hline 12 & Ceilings and walls & 15545000000 & 1.7 & 288755 & 53833 \\
\hline 13 & Baseball/softball & 14942000000 & 1.6 & 280869 & 53197 \\
\hline 14 & Tables & 13908000000 & 1.5 & 284042 & 48965 \\
\hline 15 & Soccer & 12256000000 & 1.3 & 215466 & 56880 \\
\hline 16 & All-terrain vehicles & 12223000000 & 1.3 & 133144 & 91805 \\
\hline 17 & Sofas & 11663000000 & 1.3 & 168029 & 69410 \\
\hline 18 & Wheelchairs & 10102000000 & 1.1 & 123839 & 81570 \\
\hline 19 & Porches/balconies & 9864000000 & 1.1 & 130760 & 75435 \\
\hline 20 & Furniture, NS & 9753000000 & 1.1 & 113685 & 85786 \\
\hline 21 & Knives & 9312000000 & 1.0 & 347257 & 26815 \\
\hline 22 & Containers, NS & 9115000000 & 1.0 & 113492 & 80318 \\
\hline 23 & Crutches/canes/walkers & 8430000000 & 0.9 & 104174 & 80926 \\
\hline 24 & Skateboards & 8053000000 & 0.9 & 135958 & 59233 \\
\hline 25 & Horseback riding & 7796000000 & 0.9 & 73172 & 106551 \\
\hline 26 & Footwear & 7711000000 & 0.8 & 129899 & 59359 \\
\hline 27 & Rugs/carpets & 6873000000 & 0.8 & 95164 & 72220 \\
\hline 28 & Toilets & 6691000000 & 0.7 & 77675 & 86145 \\
\hline 29 & Cabinets/shelves, NEC & 6576000000 & 0.7 & 124964 & 52625 \\
\hline 30 & Weight lifting & 6117000000 & 0.7 & 87555 & 69869 \\
\hline 31 & Dirt/trail bikes & 6001000000 & 0.7 & 68332 & 87818 \\
\hline 32 & Desks/chests/bureaus & 5953000000 & 0.7 & 106753 & 55760 \\
\hline 33 & Fences and fence posts & 5516000000 & 0.6 & 99209 & 55596 \\
\hline 34 & Trampolines & 5265000000 & 0.6 & 93721 & 56179 \\
\hline 35 & First aid equipment & 5177000000 & 0.6 & 46266 & 111903 \\
\hline 36 & Monkey bars & 5100000000 & 0.6 & 79236 & 64362 \\
\hline 37 & Swimming pools & 5038000000 & 0.6 & 65334 & 77107 \\
\hline 38 & Windows & 4777000000 & 0.5 & 108466 & 44038 \\
\hline 39 & Skating & 4299000000 & 0.5 & 71228 & 60351 \\
\hline 40 & Snow skiing & 4186000000 & 0.5 & 46117 & 90763 \\
\hline 41 & Televisions & 3931000000 & 0.4 & 55956 & 70253 \\
\hline 42 & Poisoning & 3879000000 & 0.4 & 80027 & 48466 \\
\hline 43 & Swings/swingsets & 3854000000 & 0.4 & 64489 & 59770 \\
\hline 44 & Sports and recreation, NEC & 3737000000 & 0.4 & 71889 & 51988 \\
\hline 45 & Snow boarding & 3722000000 & 0.4 & 54993 & 67688 \\
\hline 46 & Swimming & 3702000000 & 0.4 & 78848 & 46953 \\
\hline 47 & Exercise equipment & 3518000000 & 0.4 & 55236 & 63691 \\
\hline 48 & Manual snow/ice tools & 3516000000 & 0.4 & 34977 & 100532 \\
\hline 49 & Toys & 3469000000 & 0.4 & 85009 & 40808 \\
\hline 50 & Hot water & 3396000000 & 0.4 & 37230 & 91214 \\
\hline \multirow[t]{2}{*}{51} & Dancing & 3354000000 & 0.4 & 51572 & 65036 \\
\hline & Total & 909481000000 & 100.0 & 14324811 & 63490 \\
\hline
\end{tabular}

NEC, Not elsewhere classified; NS, Not specified.

between 5\% and 6\% of total product related injury costs, slightly greater than their contribution in 1995-1996.

\section{DISCUSSION}

The findings of this study highlight priority areas for intervention and generate questions for future research.
The reduction in the proportionate costs due to stair and step related injuries among those under age 1 year was notable and likely reflects the reduction in baby walker injuries seen since CPSC regulation in 1997 required baby walkers to meet safety standards designed to reduce falls down stairs. An evaluation of this regulation found that stair fall requirements prevented an 
Table 3 Leading products by age group, ranked by non-fatal injury cost, USA, 2009-2010

\begin{tabular}{|c|c|c|c|c|c|c|c|c|c|c|c|c|c|c|}
\hline Rank & $<1$ & $1-4$ & $5-9$ & $10-14$ & $15-19$ & $20-24$ & $25-29$ & 30-39 & $40-49$ & $50-59$ & $60-69$ & $70-79$ & $\geq 80$ & All ages \\
\hline \multirow[t]{2}{*}{1} & $\begin{array}{l}\text { Beds and } \\
\text { bedding }\end{array}$ & $\begin{array}{l}\text { Beds and } \\
\text { bedding }\end{array}$ & Bicycles & Football & Football & Stairs & Stairs & Stairs & Stairs & Stairs & Stairs & Floors & Floors & Stairs \\
\hline & $22.2 \%$ & $9.1 \%$ & $7.7 \%$ & $14.3 \%$ & $12.8 \%$ & $9.8 \%$ & $11.1 \%$ & $12.9 \%$ & $14.1 \%$ & $14.5 \%$ & $14.5 \%$ & $21.8 \%$ & $28.7 \%$ & $10.1 \%$ \\
\hline \multirow[t]{2}{*}{2} & Floors & Floors & Monkey bars & Bicycles & Basketball & Basketball & Basketball & Floors & Floors & Floors & Floors & Stairs & $\begin{array}{l}\text { Beds and } \\
\text { bedding }\end{array}$ & Floors \\
\hline & $13.8 \%$ & $7.2 \%$ & $6.8 \%$ & $8.4 \%$ & $11.3 \%$ & $6.8 \%$ & $4.4 \%$ & $5.0 \%$ & $6.6 \%$ & $9.8 \%$ & $13.8 \%$ & $12.4 \%$ & $11.9 \%$ & $8.9 \%$ \\
\hline \multirow[t]{2}{*}{3} & Sofas & Stairs & $\begin{array}{l}\text { Beds and } \\
\text { bedding }\end{array}$ & Basketball & Bicycles & Bicycles & Floors & Bicycles & Bicycles & Bicycles & $\begin{array}{l}\text { Beds and } \\
\text { bedding }\end{array}$ & $\begin{array}{l}\text { Beds and } \\
\text { bedding }\end{array}$ & Stairs & $\begin{array}{l}\text { Beds and } \\
\text { bedding }\end{array}$ \\
\hline & $6.6 \%$ & $7.1 \%$ & $4.6 \%$ & $8.3 \%$ & $4.8 \%$ & $4.6 \%$ & $4.4 \%$ & $4.0 \%$ & $5.0 \%$ & $5.2 \%$ & $5.7 \%$ & $8.1 \%$ & $8.5 \%$ & $4.9 \%$ \\
\hline \multirow[t]{2}{*}{4} & Stairs & Tables & Floors & Soccer & Soccer & Football & Bicycles & Basketball & Ladders & Ladders & Ladders & Chairs & Chairs & Bicycles \\
\hline & $6.0 \%$ & $5.1 \%$ & $4.0 \%$ & $4.9 \%$ & $4.7 \%$ & $3.7 \%$ & $4.3 \%$ & $2.8 \%$ & $3.6 \%$ & $4.3 \%$ & $4.5 \%$ & $5.0 \%$ & $5.9 \%$ & $4.3 \%$ \\
\hline \multirow[t]{2}{*}{5} & Car seats & Chairs & Football & $\begin{array}{l}\text { Baseball } \\
\text { /softball }\end{array}$ & Stairs & Floors & ATVs & Ladders & $\begin{array}{l}\text { Beds and } \\
\text { bedding }\end{array}$ & $\begin{array}{l}\text { Beds and } \\
\text { bedding }\end{array}$ & Chairs & $\begin{array}{l}\text { Bathtubs } \\
\text { /showers }\end{array}$ & $\begin{array}{l}\text { Crutches /canes } \\
\text { /walkers }\end{array}$ & Football \\
\hline & $5.1 \%$ & $4.6 \%$ & $3.4 \%$ & $4.7 \%$ & $4.5 \%$ & $3.4 \%$ & $2.9 \%$ & $2.7 \%$ & $3.4 \%$ & $4.1 \%$ & $3.6 \%$ & $3.6 \%$ & $5.7 \%$ & $3.0 \%$ \\
\hline \multirow[t]{2}{*}{6} & Tables & Sofas & Trampolines & Skateboards & $\begin{array}{l}\text { Baseball } \\
\text { Isoftball }\end{array}$ & ATVs & Football & $\begin{array}{l}\text { Beds and } \\
\text { bedding }\end{array}$ & $\begin{array}{l}\text { Bathtubs } \\
\text { /showers }\end{array}$ & $\begin{array}{l}\text { Bathtubs } \\
\text { /showers }\end{array}$ & Bicycles & $\begin{array}{l}\text { Crutches /canes } \\
\text { /walkers }\end{array}$ & Wheelchairs & Basketball \\
\hline & $3.2 \%$ & $4.0 \%$ & $3.4 \%$ & $3.9 \%$ & $4.1 \%$ & $3.2 \%$ & $2.7 \%$ & $2.7 \%$ & $2.8 \%$ & $3.2 \%$ & $3.5 \%$ & $3.3 \%$ & $5.0 \%$ & $2.8 \%$ \\
\hline \multirow[t]{2}{*}{7} & Chairs & $\begin{array}{l}\text { Drugs and } \\
\text { medications }\end{array}$ & Stairs & Stairs & Skateboards & $\begin{array}{l}\text { Ceilings and } \\
\text { walls }\end{array}$ & Exercise & Exercise & Exercise & Exercise & $\begin{array}{l}\text { Bathtubs } \\
\text { /showers }\end{array}$ & Wheelchairs & $\begin{array}{l}\text { Bathtubs } \\
\text { Ishowers }\end{array}$ & Chairs \\
\hline & $2.8 \%$ & $3.7 \%$ & $3.1 \%$ & $3.0 \%$ & $3.2 \%$ & $2.8 \%$ & $2.6 \%$ & $2.7 \%$ & $2.7 \%$ & $2.7 \%$ & $3.3 \%$ & $3.0 \%$ & $3.1 \%$ & $2.5 \%$ \\
\hline \multirow[t]{2}{*}{8} & Baby strollers & Doors & Doors & Floors & $\begin{array}{l}\text { Ceilings and } \\
\text { walls }\end{array}$ & Exercise & $\begin{array}{l}\text { Baseball } \\
\text { /softball }\end{array}$ & Furniture, NS & Furniture, NS & Chairs & Wheelchairs & Ladders & Toilets & $\begin{array}{l}\text { Bathtubs } \\
\text { /showers }\end{array}$ \\
\hline & $2.4 \%$ & $3.7 \%$ & $2.8 \%$ & $2.1 \%$ & $2.5 \%$ & $2.5 \%$ & $2.6 \%$ & $2.4 \%$ & $2.3 \%$ & $2.4 \%$ & $2.2 \%$ & $2.6 \%$ & $2.6 \%$ & $2.2 \%$ \\
\hline \multirow[t]{2}{*}{9} & Cribs & $\begin{array}{l}\text { Ceilings and } \\
\text { walls }\end{array}$ & $\begin{array}{l}\text { Swings/ swing } \\
\text { sets }\end{array}$ & $\begin{array}{l}\text { Sports and rec, } \\
\text { NEC }\end{array}$ & Floors & $\begin{array}{l}\text { Baseball } \\
\text { /softball }\end{array}$ & $\begin{array}{l}\text { Beds and } \\
\text { bedding }\end{array}$ & ATVs & $\begin{array}{l}\text { Containers, } \\
\text { NS }\end{array}$ & Containers, NS & Exercise & Toilets & Rugs/ carpets & Ladders \\
\hline & $2.2 \%$ & $2.3 \%$ & $2.8 \%$ & $2.0 \%$ & $2.1 \%$ & $2.2 \%$ & $2.5 \%$ & $2.3 \%$ & $2.1 \%$ & $1.6 \%$ & $2.0 \%$ & $1.9 \%$ & $2.6 \%$ & $2.1 \%$ \\
\hline \multirow[t]{2}{*}{10} & $\begin{array}{l}\text { Shopping } \\
\text { carts }\end{array}$ & Shopping carts & Slides & Trampolines & ATVs & $\begin{array}{l}\text { Beds and } \\
\text { bedding }\end{array}$ & $\begin{array}{l}\text { Ceilings and } \\
\text { walls }\end{array}$ & $\begin{array}{l}\text { Bathtubs } \\
\text { /showers }\end{array}$ & Chairs & Wheel-chairs & Toilets & Rugs/ carpets & Tables & Exercise \\
\hline & $1.9 \%$ & $1.9 \%$ & $2.5 \%$ & $1.9 \%$ & $2.0 \%$ & $2.2 \%$ & $2.3 \%$ & $2.3 \%$ & $1.9 \%$ & $1.5 \%$ & $1.5 \%$ & $1.9 \%$ & $1.9 \%$ & $1.8 \%$ \\
\hline \multirow[t]{2}{*}{11} & High chairs & $\begin{array}{l}\text { First aid } \\
\text { equipment }\end{array}$ & $\begin{array}{l}\text { Baseball } \\
\text { /softball }\end{array}$ & $\begin{array}{l}\text { Ceilings and } \\
\text { walls }\end{array}$ & Wrestling & Soccer & $\begin{array}{l}\text { Bathtubs } \\
\text { /showers }\end{array}$ & $\begin{array}{l}\text { Baseball } \\
\text { /softball }\end{array}$ & ATVs & $\begin{array}{l}\text { Porches/ } \\
\text { balconies }\end{array}$ & Doors & Doors & Doors & Doors \\
\hline & $1.8 \%$ & $1.8 \%$ & $2.2 \%$ & $1.7 \%$ & $1.9 \%$ & $2.1 \%$ & $2.0 \%$ & $2.0 \%$ & $1.7 \%$ & $1.5 \%$ & $1.5 \%$ & $1.5 \%$ & $1.5 \%$ & $1.7 \%$ \\
\hline \multirow[t]{2}{*}{12} & $\begin{array}{l}\text { Baby bouncer } \\
\text { seats }\end{array}$ & Bicycles & Scooters & Skating & Dirt/trail bikes & Doors & Knives & $\begin{array}{l}\text { Containers, } \\
\text { NS }\end{array}$ & $\begin{array}{l}\text { Porches/ } \\
\text { balconies }\end{array}$ & $\begin{array}{l}\text { Horseback } \\
\text { riding }\end{array}$ & $\begin{array}{l}\text { Porches/ } \\
\text { balconies }\end{array}$ & Tables & $\begin{array}{l}\text { Ceilings and } \\
\text { walls }\end{array}$ & $\begin{array}{l}\text { Ceilings and } \\
\text { walls }\end{array}$ \\
\hline & $1.6 \%$ & $1.8 \%$ & $1.9 \%$ & $1.7 \%$ & $1.7 \%$ & $2.1 \%$ & $1.9 \%$ & $1.8 \%$ & $1.5 \%$ & $1.4 \%$ & $1.4 \%$ & $1.5 \%$ & $1.4 \%$ & $1.7 \%$ \\
\hline
\end{tabular}

ATVs, all-terrain vehicles; NEC, Not elsewhere classified; NS, Not specified. 
Table 4 Leading products, ages 5-24 years, ranked by cost of non-fatal injuries, 2009-2010 (2009 dollars)

\begin{tabular}{|c|c|c|c|c|c|}
\hline Rank & Product & Annual total cost (\$) & Percentage & Annual incidence & Mean cost $(\$)$ \\
\hline 1 & Football & 23358000000 & 9.5 & 418892 & 55761 \\
\hline 2 & Basketball & 18080000000 & 7.4 & 404237 & 44726 \\
\hline 3 & Bicycles & 16165000000 & 6.6 & 307457 & 52578 \\
\hline 4 & Stairs & 11664000000 & 4.8 & 261783 & 44555 \\
\hline 5 & Soccer & 8847000000 & 3.6 & 175935 & 50283 \\
\hline 6 & Baseball/softball & 8662000000 & 3.5 & 192279 & 45050 \\
\hline 7 & Floors & 6866000000 & 2.8 & 129725 & 52930 \\
\hline 8 & Skateboards & 6691000000 & 2.7 & 118526 & 56455 \\
\hline 9 & Ceilings and walls & 5258000000 & 2.1 & 128185 & 41018 \\
\hline 10 & Beds and bedding & 5194000000 & 2.1 & 109077 & 47618 \\
\hline 11 & Doors & 4537000000 & 1.8 & 122066 & 37166 \\
\hline 12 & All-terrain vehicles & 4482000000 & 1.8 & 64236 & 69775 \\
\hline 13 & Monkey bars & 4185000000 & 1.7 & 64946 & 64436 \\
\hline 14 & Trampolines & 3778000000 & 1.5 & 71227 & 53040 \\
\hline 15 & Exercise (w/o equipment) & 3246000000 & 1.3 & 65438 & 49597 \\
\hline 16 & Sports and recreation, NEC & 3105000000 & 1.3 & 63493 & 48899 \\
\hline \multirow[t]{2}{*}{17} & Dirt/trail bikes & 3091000000 & 1.3 & 42870 & 72099 \\
\hline & Total & 245456000000 & 100.0 & 5236607 & 46873 \\
\hline
\end{tabular}

NEC, Not elsewhere classified.

estimated $60 \%$ of baby walker injuries. ${ }^{3}$ A follow-up analysis found that net benefits from the regulation totalled $\$ 169$ per baby walker's product life. ${ }^{4}$

While much progress has been made in preventing stair related injuries among children, ${ }^{2}$ stairs still contributed substantially to injury costs among those over age 19 years. Thus intervention to prevent stair related injuries should continue to be a priority. Based on 34 years of NEISS data, Pauls ${ }^{5}$ found that stair related injuries in homes increased steadily from 1998 to 2006, a period that coincided with increased use of prefabricated stairs in new homes. When fitting prefabricated stairs into a home, the top step will often have a different rise/run ratio than lower steps in the same flight. Non-uniform step geometry has been shown to increase the risk of falls on stairs. Another priority area for intervention among the elderly is bathroom related injuries.

Among 5-24-year-olds, sports related injuries dominated injury costs. Notably, football is now appearing among the top five product injury cost contributors among 5-9-year-olds. In 1995-1996 it was not in the top 10. The contribution of soccer is also increasing among 5-24-year-olds. The change cannot be attributed to changes in participation. In fact, national data show that participation in football in 2010 was at levels similar $(-2 \%)$ to 1995 and participation in soccer has declined dramatically since $1995(-16 \%){ }^{6}$ Increases in severity of injury, including increased numbers of traumatic brain injuries (TBI), may play a role in the increases in sport related injury costs. An analysis of 2001-2009 NEISS data noted that the number of sports and recreation related ED visits for TBI among 0-19-year-olds increased by $62 \%$ in this period, with football, basketball and soccer as leading causes. ${ }^{7}$ The study also noted that the increase was likely due to increases in awareness of TBI. Further exploration of the factors driving the increase in sports related injury costs, in particular for soccer and football among children 5-19 years, is a priority.

Exercise is rising in importance as a cause of consumer product related injury, especially among the middle age groups. The change may be as result of increasing informal physical activity, such as jogging and walking, in these age groups and merits observation for future trends.

\section{Fatal consumer product related injury}

This study was limited to non-fatal injuries. NEISS and NEISS-AIP are not suitable datasets for analysing fatal injuries, and the ICM is not designed to estimate the costs of fatal injuries. Schroeder, ${ }^{8}$ using established CPSC methods with Vital Statistics data, estimated that there were 35900 product related injury deaths in 2008. Applying a value of statistical life of $\$ 5$ million, that would come to $\$ 179.5$ billion dollars-about $20 \%$ of our estimated cost of non-fatal consumer product injuries.

In 2009-2010, according to Vital Statistics data, there were 164336 unintentional, non-transport related injury deaths in the USA. This can be taken as an upper bound on the number of fatal consumer product injuries. According to our estimates, these injuries would result in an annual cost to society of $\$ 328.5$ billion dollars-about $36 \%$ of our estimated cost of non-fatal consumer product injuries.

\section{Limitations}

First, since the ICM cost estimates are based on NEISS incidence estimates, they also necessarily embody the limitations of the NEISS sample. NEISS estimates based on small case counts will lack statistical reliability, and ICM estimates of aggregate costs for those cases should be regarded with caution.

Second, the ICM does not estimate costs for a large body of injuries where no medical treatment was sought, but whose victims restricted their activities for at least a half day. These injuries are self-diagnosed, and their severity is difficult to assess. These activity restricting injuries consist primarily of cracked ribs, strains, contusions and superficial injuries. While costs for these relatively minor injuries are difficult to assess, we estimate that they number some 12 million. Additional study of these injuries may suggest innovative costing methods. However, any costs developed are likely to be a small fraction of total costs estimated by the ICM. 
Third, the limited purpose of the ICM-estimating the cost of non-fatal injuries caused by consumer products-must be kept in mind when interpreting the cost estimates and product rankings. The estimated $\$ 43$ billion cost of the 21500 annual consumer product fatalities is not distributed by product category. (The $\$ 2$ million value per fatality is our estimate, based on a review of awards for consumer product injury deaths, of the average wrongful death award.) If fatal injury cases contribute disproportionately to costs across product categories, their inclusion might alter the product rankings. Additionally, certain products are excluded from this analysis because the CPSC does not have jurisdiction over them-most notably, motor vehicles and firearms, which annually cause a substantial number of injuries as well as fatalities. We estimate that non-fatal injuries due to MVCs (excluding crashes with motorcycles, pedal cycles and pedestrians) cost $\$ 85.5$ billion (in 1997 dollars), nearly twice the cost of injuries associated with stairs, the first place consumer product, at $\$ 46.7$ billion. Non-fatal unintentional firearm injuries cost $\$ 14.2$ billion, ${ }^{9}$ which would put gun related injuries in eighth place in terms of injury costs (with MVCs included in the rankings), after baseball/softball and ahead of football, doors, chairs and ladders.

Fourth, this analysis does not examine product exposure, which may influence the incidence and costs of injuries across products. Some products (eg, chainsaws) may be associated with a small number of injuries because they are used infrequently, while more widely used and safer products (eg, kitchen knives) may be associated with higher levels of injuries and costs. The current analysis fails to separate exposure and products' inherent level of danger or risk.

Fifth, friction costs ${ }^{10}$ would measure the indirect costs to the employer of replacing disabled workers more accurately than the ICM employer cost estimates. However, estimates of USA friction costs do not exist. Computing them would be an ambitious undertaking beyond the scope of the ICM project.

\section{What is already known on the subject?}

- Products under the purview of the Consumer Product Safety Commission are involved in a large share of injuries and injury costs in the USA.

- Annually, these product related injuries account for approximately $29 \%$ of unintentional injury deaths.

- Non-fatal consumer product related injuries cost approximately $\$ 500$ billion per year in 1995-1996.

\section{What this study adds}

- This study highlights the leading consumer products responsible for non-fatal injury costs, by age group, from 2009 to 2010.

- The findings generate questions for future research.

Acknowledgements The study was supported by the Maternal and Child Health Bureau, Health Resources and Services Administration, US Department of Health and Human Services under the Children's Safety Network National Injury and Violence Prevention Resource Center prime contract U49 MC07 499 and subcontract 11474 PIRE. All views expressed herein and any errors or omissions are those of the authors and may not reflect those of the US Department of Health and Human Services.

Contributors BAL and TRM both made substantial contributions to the study's conception and design. BAL performed the analysis and drafted the first version of the paper. RSS contributed to the interpretation of the data and wrote the final version of the paper. All three authors have read and approved this final version for publication. All three authors are responsible for the overall content as guarantors.

\section{Competing interests None.}

Provenance and peer review Not commissioned; externally peer reviewed.

\section{REFERENCES}

1 Lawrence BA, Miller TR, Jensen AF, et al. Estimating the costs of non-fatal consumer product injuries in the United States. Inj Contr Saf Promot 2000;7:97-113

2 Zielinski AE, Rochette LM, Smith GA. Stair-related injuries to young children treated in US emergency departments, 1999-2008. Pediatrics 2012;129:721-7.

3 Rodgers GB, Leland EW. An evaluation of the effectiveness of a baby walker safety standard to prevent stair-fall injuries. J Saf Res 2005;36:327-32.

4 Rodgers GB, Leland EW. A retrospective benefit-cost analysis of the 1997 stair-fall requirements for baby walkers. Accid Anal Prev 2008;40:61-8.

5 Pauls J. Injurious falls on stairways: background for international conference in June 2011. Proceedings of International Conference on Slips, Trips and Falls, STF2011. UK: Health and Safety Laboratory, 2011.

6 NSGA, National Sporting Goods Association. Sports Participation in the United States. Mount Prospect, IL, 2011.

7 CDC. Nonfatal traumatic brain injuries from sports and recreation activities among persons aged $\leq 19$ years_-United States, 2001-2009. MMWR Morb Mortal Wkly Rep 2011;60:1337-42.

8 Schroeder T. Consumer product-related injuries and deaths in the United States: Estimated injuries occuring in 2010 and estimated deaths occuring in 2008. Bethesda, MD: US Consumer Product Safety Commission, 2012.

9 Miller TR, Romano EO, Spicer RS. The cost of childhood unintentional injuries and the value of prevention. Future Child 2000;10:137-63.

10 Koopmanschapp MA, Rutten FFH, van Ineveld BM, et al. The friction cost method for estimating the indirect costs of disease. J Health Econ 1995;14:171-89. 